\title{
Improved Alum Containing Adjuvant by Vitamin A for Enhancing Immune Responses and Efficacy of Leptospira Vaccine in Hamster Model
}

\section{Reza Banihashemia ${ }^{1 *}$, Behzad Baradaran ${ }^{2}$, Majid Tebianian ${ }^{1}, K_{\text {Tadayon }}^{3}$, Seyed Mahmod Ebrahimi ${ }^{4}$ and Mohammad H Hablolvarid $^{1}$}

${ }^{1}$ Department of Immunology, Razi Vaccine Serum Research Institute, Karaj, Iran

${ }^{2}$ Immunology Research Center, Tabriz University of Medical Sciences, Tabriz, Iran

${ }^{3}$ Aerobic Department of, Razi Vaccine Serum Research Institute, Karaj,Iran

${ }^{4}$ Applied Biotechnology Research Center, Baqiyatallah University of Medical Sciences, PO Box 14155-3651, Tehran, Iran

*Corresponding Author: Reza Banihashemi, Department of Immunology, Razi Vaccine Serum Research Institute, Karaj, postal code-3197619751, Iran, Tel: +98 (26) 34502749; +989126134324; E-mail: Reza7471@gmail.com; r.banihashemi@RVSRI.ac.ir

Received date: September 03, 2016; Accepted date: October 17, 2016; Published date: October 20, 2016

Copyright: (c) 2016 Banihashemia R, et al. This is an open-access article distributed under the terms of the Creative Commons Attribution License, which permits unrestricted use, distribution, and reproduction in any medium, provided the original author and source are credited.

\begin{abstract}
Use of suitable adjuvant is one of the priorities in vaccine and immune modulation, stimulation and potentiating. Vaccination is effective for prevention and treatment of bacterial diseases including Leptospirosis. In the present study, we prepared Leptospiral vaccine with Alum, modified Alum adjuvant (mAlum) and without adjuvant. Vaccination was done; then we evaluated the immune responses by isolating the splenocytes and sera for interleukin (IL) profiles (the highest level of all cytokines except IL-4 and IL-12 was obtained in the mAlum antigen group at week 7 post-treatment). Moreover, the expression of all evaluated cytokines in the mAlum group was greater than in the other groups at week 62. Significant increases in antibody titters were noted in the mAlum and Alum group, challenged interaperitionelly with a lethal dose of virulent and monitored pathological lesion that moderate to severe lesions with score 3 were observed in the control group while the animals immunized with mAlum-antigen and Alum-antigen displayed slight to mild lesions with an average score of 0.5 . The results demonstrated that modified Alum Adjuvants are better than Alum adjuvants as revealed by the enhanced long-term antibody responses. None of the vaccinated animals died from the challenge experiment 84 day post-injection except those vaccinated with saline vaccine. We assume that these observations affirmatively assign a pivotal vitamin a role to adjuvant formulation and preparation in type and extent of immune responses raised in the vaccinated animals.
\end{abstract}

Keywords: Vaccine; Adjuvant; Immunomodulation; Cytokine; Vitamin A

\section{Introduction}

Vaccination as an effective way for prevention and treatment of bacterial diseases like leptospirosis has been widely applied over the last century [1]. Leptospirosis is a zoonotic disease in the developed countries. Many problems following leptospirosis occur in the livestock industry, tourism and sport. Despite enormous efforts to eradicate the disease, more than 500,000 cases are reported each year. Vaccines against leptospirosis were published in 1916 [2]. Since then; whole cell vaccines have been used in humans, cattle, swine, and dogs. However, this type of vaccine has many problems, especially ineffectiveness [1]. In recent year, considerable attempts have been made for improvement of vaccine industry to increase the immune duration, safety and prophylaxis. Induction of the favourable immune response is the ideal goal; however, it is hard to obtain because of the wide varieties broad relationships between immune cells, cytokines, hormones and the nervous system [3]. Accordingly, as noted Kool et al., a more complete understanding of the mechanisms for immunopotentiation/regulation/ modulation and safety is necessary [2]. The immune system regulation is highly depended on the balance between signalling proteins and molecule. Proinflammatory cytokines such as (INF)- $\delta$, tumor necrosis factor (TNF)- $\alpha$, interleukin IL-1, IL-6, and IL-12 not only regulate protective immunity against pathogens, but also are involved in induction of some immunophatologies [4,5]. Several of these biologic effects are also evident during host responses to leptospira [6,7]. For example, increased levels of TNFa, IL-12 and IFN- $\delta$ were detected in patients with acute several leptospirosis [3]. It was also seen that IFN- $\delta$ could be responsible for a protective role in hosts (i.e., bovine) that had been previously vaccinated with heat killed L.borgpetersenii serovar Harjo [8]. In general, choosing an appropriate adjuvant for stimulation of the innate immune system and preservation of antigens from degradation is important. As part of their effect on host responses to specific antigens, adjuvants have a capability to stimulate release of various $\mathrm{TH} 1$ and $\mathrm{TH} 2$ cytokines and, ultimately in most cases, humeral responses.

Previous studies have implicated that some components, such as vitamins, could be used for increasing of adjuvants ability [9]. Vitamins could play essential roles in regulating and modulating a broad range of immune functions, such as lymphocyte activation and differentiation, tissue-specific lymphocyte homing and production of specific antibody isotypes. Currently, there are some adjuvants which have been formulated by Vitamin E [9-11]. In this study, different formulation of adjuvants with Leptospira vaccine have been studied for their ability on the induction of cellular and humeral immune responses ideal goals were to gain the maximum immune duration, immunomodulatory effects, and affinity of antibody, lymphoprolifration assay, interleukin pattern, and prophylaxis prior challenges.

Materials and Methods 
Citation: Banihashemia R, Baradaran B, Tebianian M, Tadayon K, Ebrahimi SM, et al. (2016) Improved Alum Containing Adjuvant by Vitamin A for Enhancing Immune Responses and Efficacy of Leptospira Vaccine in Hamster Model. J Vaccines Vaccin 7: 342 . doi: $10.4172 / 2157-7560.1000342$

Page 2 of 7

\section{Leptospira and adjuvant preparation}

The three different Leptospira serovar including L.serovars (sejroe hardjo, canicola and grippotyphosa) were obtained from Razi vaccine and serum research institute (RVSRI), Karaj, Iran [3].

The bacteria were grown in a low protein chemical medium (Banihashemi et al.) suitable for Leptospira cultivation. Specifically, the three serovar including were cultured in the media at $27^{\circ} \mathrm{C}$ fore $72 \mathrm{hr}$ and then inactivated using $0.4 \%$ formalin. All the material utilized in the medium was obtained from Merck Company.

For uses in these studies, adjuvant comprised of $2.5 \% \mathrm{AL}(\mathrm{OH})_{3}$ aluminium hydroxide gel produced by $\mathrm{ALCL}_{3}(2.5 \%)$ and $\mathrm{KHPO}_{4} \mathrm{mg}$ ), $\mathrm{NaCl}$ (15.6 mg), sodium acetate, and Each ml contains 500,000 IU of vitamin $\mathrm{A}$ and the physical conditions by phosphate group and decreasing the affinity antigens conjugated to the Adjuvant and standard release antigen in serum. Each adjuvants was combined separately with a sample of mixed bacterial suspension (at a final concentration $3 \times 10^{5}$ )

\section{Animals}

For this study, 90 healthy Syrian hamsters (female 4-wk-old) were purchased from the from the animal production department of Razi institute. Upon arrive, all were housed under pathogen-free condition in facilities maintained at $27^{\circ} \mathrm{C}$ with a $45 \%$ relative humidity and a 12 hr light dark cycle. All animals had ad libitum access to standard hamster chow and filtered water. All experiments were conducted according to protocols approved by the animal care and use committee (IACUC) of the Razi vaccine serum institute [3,4].

\section{Vaccination}

Prior these studies a pilot safety trial was performed with all the vaccines. For this purpose, 5 hamsters (as well as 5 mice, 5 rabbits, and guinea pigs) were injected with $0.5 \mathrm{ml}$ vaccine intrapritonealy (IP) and subcutaneously (SC). All animals were monitored for anaphylactic shock or significant local Inflammation in 14 days after injection $[3,4]$. The hamsters were randomly allocated in two groups as: experimental $(\mathrm{N}=60)$ and control $(\mathrm{N}=30)$ groups. Hamsters were $\mathrm{SC}$ inoculated with the leptospiral vaccine.

Preparations and then injected with no adjuvant only saline normal $(\mathrm{N}=20)$ Alum $(\mathrm{N}=20)$, or modified Alum $(\mathrm{N}=20)$. Control received either saline or nothing $(\mathrm{N}=10)$ or were mock-vaccine-injected and then received Alum $(\mathrm{N}=10)$ or mAlum alone $(\mathrm{n}=10)$. The vaccinated animals were subjected to booster inoculations at weeks 2 and 62 . They were immunized subcutaneously with $1 \mathrm{ml}$ of each vaccine, and boosted 2 times. The first injection was after two weeks, and the second time was on the $62^{\text {th }}$ week with the same dose. The animals were weekly bled through the saphenous vein until the week 65 . To investigate the immune duration, blood collections were conducted at weeks $3,6,9,12,15,64$ and 65 . All serum samples generated from the collected materials were kept at $-80^{\circ} \mathrm{C}$ prior to use in experimental evaluation (Table 1) [3]. The antibody responses against various vaccine preparations were evaluated by the enzyme-linked immunosorbent assay according to Banihashemi et al. [3].

\section{Ex vivo lymphoprolifration assay}

Lymphoprolifration response was evaluated against the recall antigen. Briefly all animals were euthanized by ketamin and subjected to splenectomy $[5,7,12]$. The red blood cells (RBCs) were lysed using red blood cell lysing solution (TAKARA), washed twice in HBSS, suspended in cRPMI (FLUKA), the final cell suspension was counted and viability of the cells assessed using trypan blue. To assess viability, $5 \times 10^{5}$ splenocyte was seeded in 96-well plates per each well in $200 \mu \mathrm{l}$ of complete RPMI. The seeded splenocytes were stimulated by antigens (serotype canicola) for $72 \mathrm{~h}$ at $37^{\circ} \mathrm{C}$ with $5 \% \mathrm{CO}_{2}$. Phytohemagglutinin PHA $(10 \mu \mathrm{g} / \mathrm{ml})$ and medium were used as positive and negative controls, respectively. DNA synthesis in the stimulated and control cells was measured by ELISA using BrdU colorimetric kit (Roche Diagnostics, Indianapolis, IN) according to the manufacturer's protocol.

\begin{tabular}{|l|l|l|l|l|l|l|}
\hline Group & Vaccine & Adjuvant & NO & Booster1 & $\begin{array}{l}\text { Booster } \\
\mathbf{2}\end{array}$ & Ch1 \\
\hline 1 & $\begin{array}{l}\text { Leptospira } \\
\text { vaccine }\end{array}$ & -- & 20 & 2 weeks & 62 weeks & 7 weeks \\
\hline 2 & $\begin{array}{l}\text { Leptospira } \\
\text { vaccine }\end{array}$ & Alum & 20 & 2 weeks & 62 weeks & 7 weeks \\
\hline 3 & $\begin{array}{l}\text { Leptospira } \\
\text { vaccine }\end{array}$ & mAlum & 20 & 2 weeks & 62 weeks & 7 weeks \\
\hline 4 & -- & Alum & 10 & 2 weeks & 62 weeks & 7 weeks \\
\hline 5 & -- & mAlum & 10 & 2 weeks & 62 weeks & 7 weeks \\
\hline 6 & $\begin{array}{l}\text { Saline } \\
\text { Normal }\end{array}$ & -- & 10 & 2 weeks & 62 weeks & 7 weeks \\
\hline
\end{tabular}

Table 1: Animal immunization schedule.

\section{Cytokine analysis by quantitative real-time PCR}

Total RNA isolation was performed by high pure RNA extraction Kit (Roche, Germany), cDNA synthesis was done using revert aid first strand cDNA synthesis Kit (Fermentas) and real-time quantitative RTPCR was performed according to manual SYBR premix ex Taq $\Pi$ (Ti RNaseH Plus), bulk kit (TakaRa) $[5,6,13]$. The primers used of these analyses are presented in Table 2 . The PCR cycle was $5 \mathrm{~min}$ at $95^{\circ} \mathrm{C}$, followed by 45 cycles at $95^{\circ} \mathrm{C}$ for $30 \mathrm{~s}$ and $60^{\circ} \mathrm{C}$ for $30 \mathrm{~s}$ and $75^{\circ} \mathrm{C}$ for 12 s. Quantization has used the comparative cycle threshold (CT) method by REST software, and reported as relative transcription or the $\mathrm{n}$-fold difference relative to the house keeping gene hypoxanthine phosphoribosyl transferase (HPRT) and beta Actin.

\begin{tabular}{|l|l|l|l|}
\hline Name & Slain Vaccine & mAlum Vaccine & Alum Vaccine \\
\hline TNFa & 1.26 & 9.11 & 1.86 \\
\hline IFNy & 0.51 & 3.92 & 1.36 \\
\hline IL12p40 & 0.47 & 2.14 & 1.24 \\
\hline IL4 & 0.52 & 1.82 & 1.11 \\
\hline IL10 & 0.44 & 8.41 & 4.24 \\
\hline
\end{tabular}

Table 2: Expression of cytokine mRNA after immunization with antigen plus various.

\section{Challenge}

The hamsters were challenged by intraperitoneal injection in day 49 with 10X MLD50 (modfied $\mathrm{LD}_{50}$ ) of a single passage of $L$. interrogans serovar conicola (Razi Institute), isolated from the kidney of a hamster 
Citation: Banihashemia R, Baradaran B, Tebianian M, Tadayon K, Ebrahimi SM, et al. (2016) Improved Alum Containing Adjuvant by Vitamin A for Enhancing Immune Responses and Efficacy of Leptospira Vaccine in Hamster Model. J Vaccines Vaccin 7: 342. doi: $10.4172 / 2157-7560.1000342$

Page 3 of 7

inoculated with an isogonics strain $[8,12,14]$. Survived animals after were challenged on day 97 ( 55 days after challenge), and the blood samples were collected from the cardiac puncture. The tissues of the infected animals were collected aseptically for histopathology.

\section{Histopathology}

After euthanizing of the animals, samples of the liver, kidney and lung were collected and kept at $10 \%$ buffered formalin. The tissues were processed to paraffin blocks, sectioned at $5 \mu \mathrm{m}$, deparaffinised, stained with $\mathrm{H} \& \mathrm{E}$, and finally, examined by a light microscope (NIKON, 80i). Severity of the lesions was studied by an expert pathologist. Quantify classification approach was used to evaluate the severity of the injuries. Tubulointerstitial nephritis was assessed as below: $0=$ normal, $1=$ mild, $2=$ moderate and $3=$ severe. Liver and lung pathology was graded based on the average of inflammatory foci in 10 $\times 10$ fields: $0=$ normal, $1=1-3,2=4-7$ and $3 \geq 7$. The extent of pulmonary haemorrhage was graded as $0=$ none, $1=$ single focus, $2=$ multiple foci, and $3=$ locally extensive (Table 3 ).

\begin{tabular}{|l|l|}
\hline Vaccine and Adjuvants & Average score after weeks 7 \\
\hline vaccine+mAlum & 0.3 \\
\hline vaccine+Alum & 0.5 \\
\hline vaccine+Saline & 1.3 \\
\hline control & 3 \\
\hline
\end{tabular}

Table 3: Averages of pathological scores in three organs including kidney, liver and lung after weeks 7.

\section{Statistical analyses}

All data are reported as mean \pm SD For the cytokine assay, change within groups over time was analysed by the paired t-test. The difference between the vaccinated and control animals was analysed using a one-way ANOVA test. The software used for the statistical analysis was STATA for windows. $\mathrm{P}<0.05$ values were considered statistically significant.

\section{Results}

\section{Characterization of vaccine}

During the 14-days of safety test observation period, no anaphylactic shock reaction or significant local inflammations was detected [3].

\section{Antibody response}

The protective efficacy of Leptospira vaccine without adjuvant was evaluated in a sensitive hamster through one year. High increase in the antibody titres was observed in the mAlum and Alum group, but an intense decrease of the antibody titres was observed in free adjuvant vaccine receiving groups. Humoral response in the immunized group after one year showed a drastic decrease of antibody titer in the without adjuvant group. These results reveal that protective efficacy of mAlum adjuvant with Leptospira vaccine is more than that of Alum adjuvant after one year. To evaluate the strength of a memory cell response, the last booster was injected in week 62 . The results after last booster showed that significant increase of antibody titre was belonged to the mAlum, Alum and without Adjuvant groups, respectively (Figure 1).

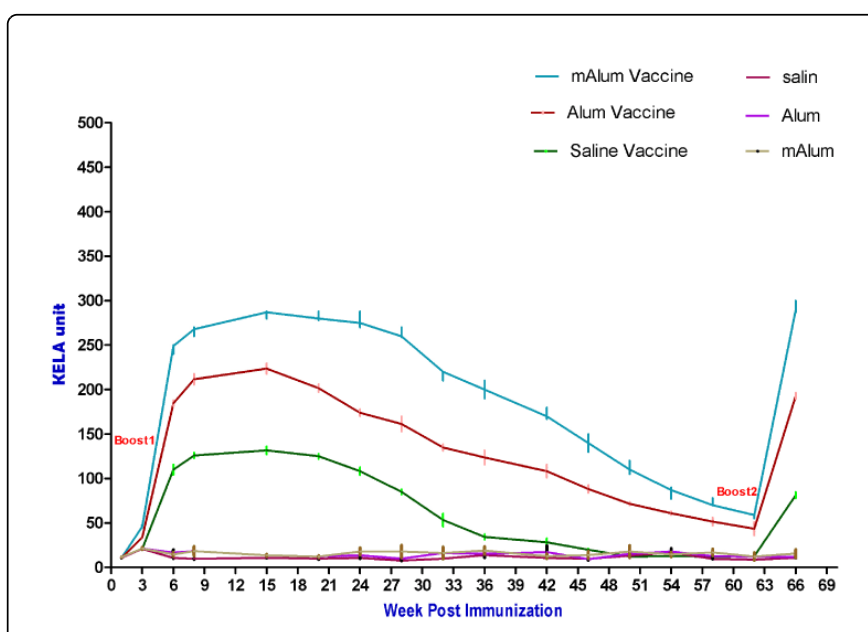

Figure 1: Antibody responses of vaccine: High increase in antibody titres was observed in the mAlum and Alum groups but intense decrease of antibody titres was observed in the groups receiving free adjuvant vaccine.

\section{Ex vivo lymphoproliferative response}

The splenocytes obtained from various groups were subjected to lymphoproliferation assay at weeks 7 and 62 (Figure 2).

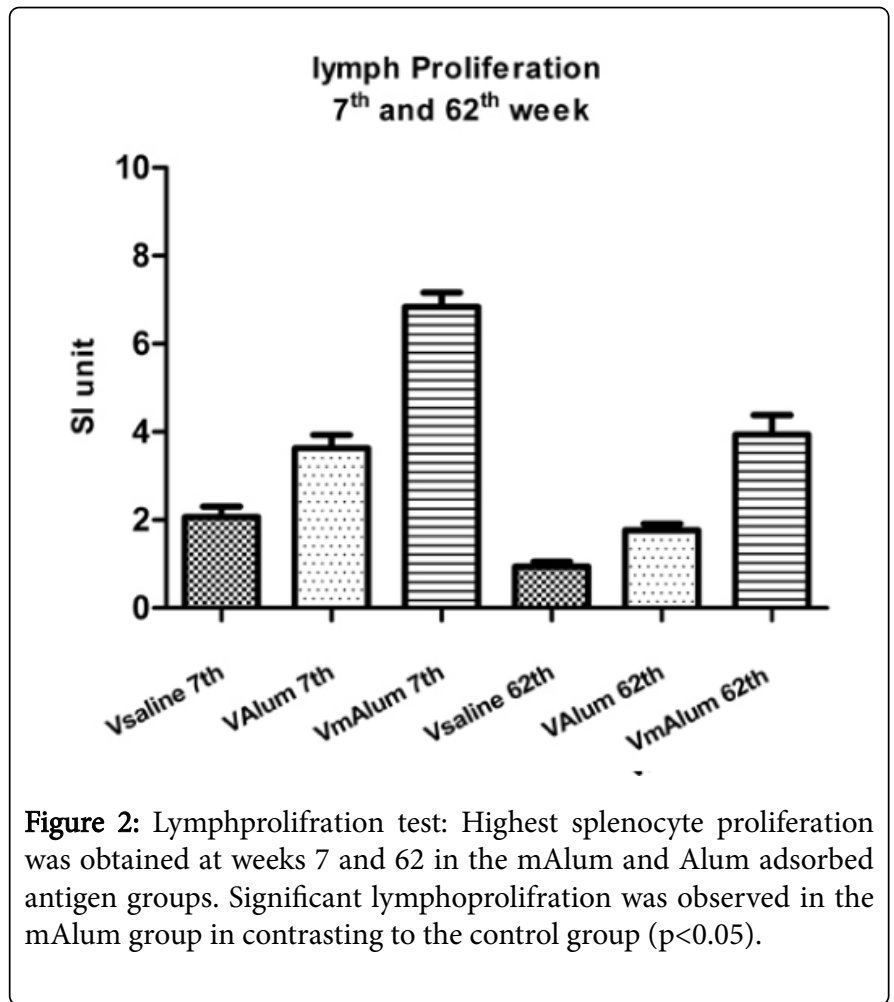

EX vivo proliferation after challenging with Leptospira canicola without adjuvant was weak compared to the seen with cell from other group, though significant lymphoprolifration was observed contrasting 
Citation: Banihashemia R, Baradaran B, Tebianian M, Tadayon K, Ebrahimi SM, et al. (2016) Improved Alum Containing Adjuvant by Vitamin A for Enhancing Immune Responses and Efficacy of Leptospira Vaccine in Hamster Model. J Vaccines Vaccin 7: 342 . doi: $10.4172 / 2157-7560.1000342$

Page 4 of 7

to the control groups $(\mathrm{p}<0.05)$. The greatest proliferation was obtained at week 7 and 62 in mAlum and Alum groups. However, the lymphoprolifration response in the group immunized with mAlum plus antigen was significantly increased in comparison to the Alum and without adjuvant combined antigen groups $(\mathrm{p}<0.05)$. Decrease in cell proliferation in weeks 62 was obtained in all groups, and the lowest reduction was observed in the mAlum antigen group. Also lymphoprolefrative responses in saline group were similar to those of the control group after 62 weeks. The splenocytes isolated from the animals immunized with PBS-adjuvants failed to show splenocyte proliferation in all groups (Figure 2). Significant splenocyte proliferation occurred in response to PHA (positive control) while groups treated with medium alone could not stimulate cell proliferation (negative control) in both the control and vaccinated groups at weeks 7 and 62 .
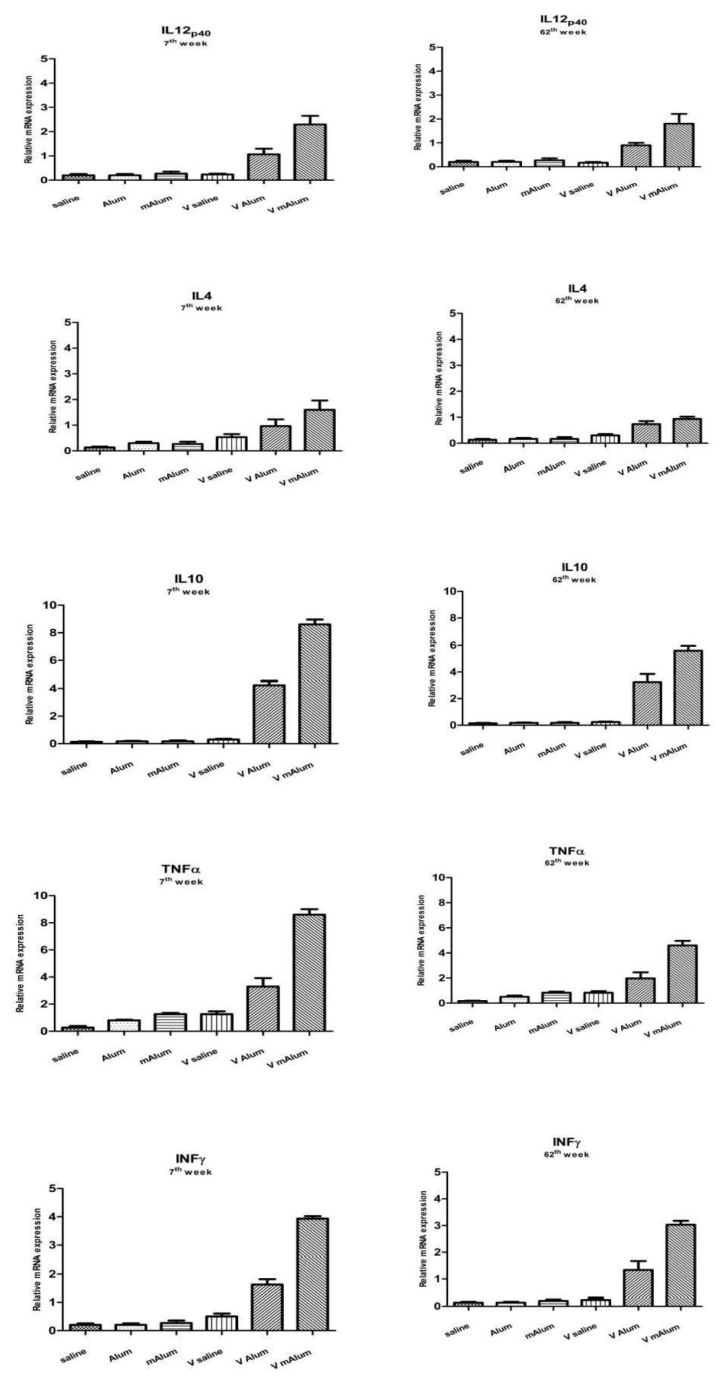

Figure 3: Expression of cytokine mRNA in weeks 7 and 62: the highest level of all Cytokines was obtained in the mAlum group at weeks 7 after treatment.

\section{Cytokine response}

The expression of both Th1 (IFN- $\gamma$, Il-12, TNF- $\alpha$ ) and Th2 (IL-4, IL-10) type cytokines was evaluated from the splenocytes stimulated by antigen with and without various adjuvants using relative quantitative real-time PCR. Based on our findings (Figure 3), the highest level of all cytokines except IL- 4 and IL-12 was obtained in the mAlum antigen group at week 7 post-treatment. Moreover, the expression of all evaluated cytokines in the mAlum group was greater than in the other groups at week 62 . High levels of Th2 cytokines, especially IL-10, were induced by the mAlum group as compared to other groups with various adjuvants $(\mathrm{p}<0.05)$. Apart from Th2 cytokines, mAlum induced a significant Th1 response specified by the elevated levels of TNF- $\alpha$ and IFN- $\gamma$. The expression of cytokines mRNA from the isolated splenocytes was dropped in all groups at week 62, but the decrease level in the mAlum group was less in comparison to the other groups. Overall, the mAlum group induced a mixed Th1/Th2 response with slight polarization to Th2 response. No significant cytokines mRNA levels of either Th1 or Th2 cytokines were observed in the control group (Figure 3).

\section{Immunopathology following challenging with various adjuvants-antigens}

The protective efficacy of antigens delivered through different adjuvants was evaluated in terms of survival and histopathology. Regarding the animal survival after immunization, the results showed $100 \%$ survival of the specimens immunized with mAlum, Alum and $60 \%$ saline vaccine 56 days post-challenging whereas none of the animals survived in the control group (Figure 4).

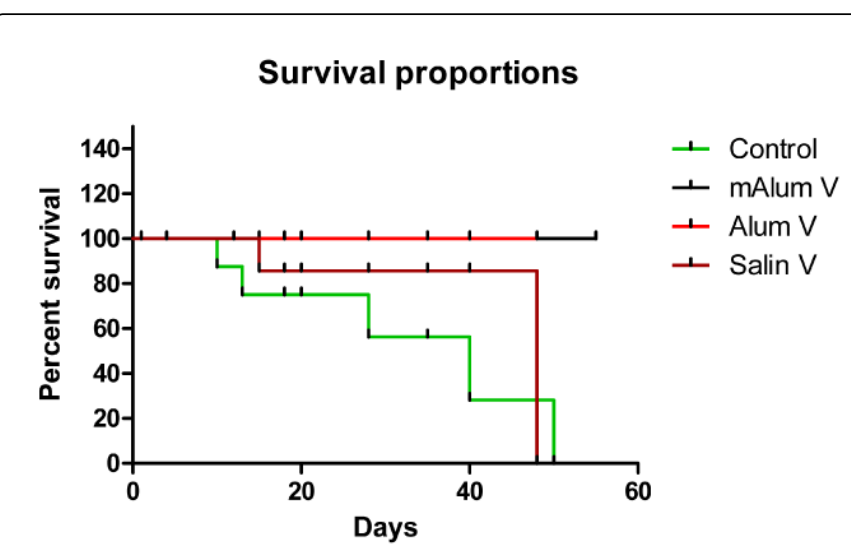

Figure 4: Survival of group four animal groups' survival after immunization, 56 days post-challenging showed $100 \%$ survival of the specimens immunized with mAlum, Alum and $60 \%$ saline vaccine, whereas none of the animals survived in the control group.

Mixture of adjuvants with antigens clearly increased the survival rate, and showed significant effects on protection. On the other hand, the histopathological evaluation of various tissues such as kidney, liver and lung in the hamsters (challenged with 10X MLD50 of Leptospira) showed alveolar oedema, pulmonary haemorrhage, inflammation, leucocytosis and cell swelling (Figure 5). Pathologic changes at week 7 were scored and are presented in Table 4. Moderate to severe lesions with the score 3 were observed in the control group while the animals immunized with mAlum-antigen and Alum-antigen displayed slight to 
Citation: Banihashemia R, Baradaran B, Tebianian M, Tadayon K, Ebrahimi SM, et al. (2016) Improved Alum Containing Adjuvant by Vitamin A for Enhancing Immune Responses and Efficacy of Leptospira Vaccine in Hamster Model. J Vaccines Vaccin 7: 342 . doi: $10.4172 / 2157-7560.1000342$

Page 5 of 7

mild lesions with an average score of 0.5 . Also, immunization with vaccine-saline caused mild lesions in the animals with the score of 1.3.

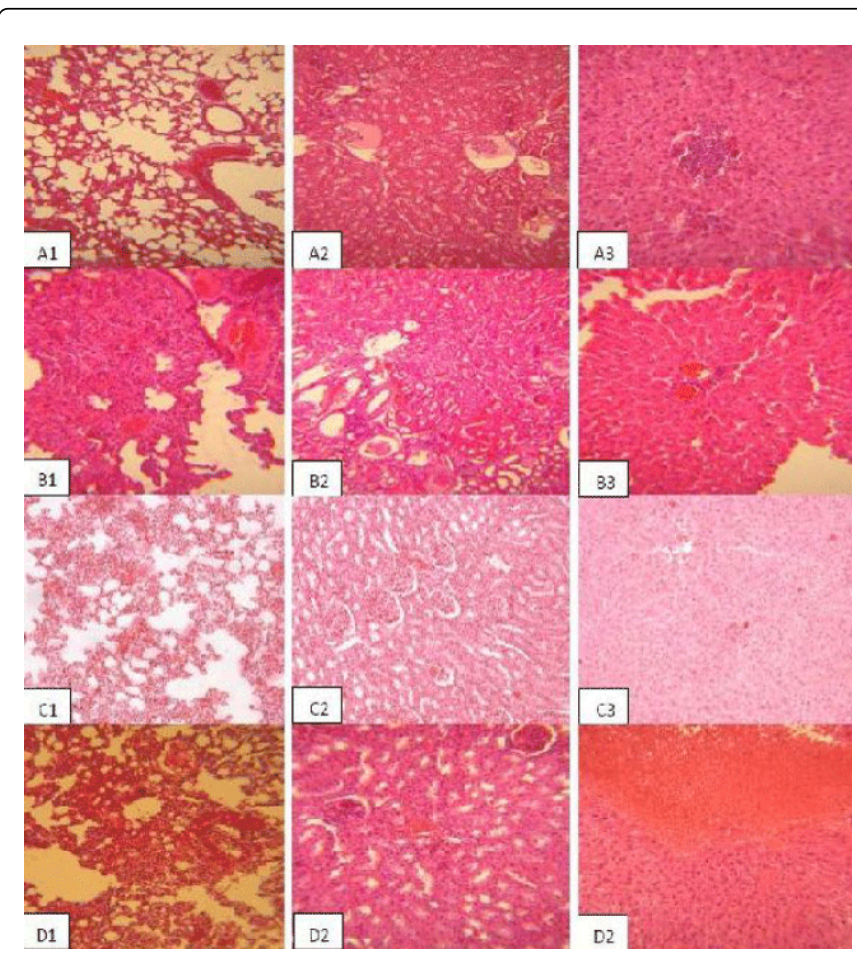

Figure 5: Histopathological lesions post-challenging of the animals with antigen and different adjuvants in each group: Left to right: pathological lesions of lung, kidney and liver Tissues are presented in columns 1,2 and 3, respectively. A: control group without vaccine And Adjuvants, B: vaccine without adjuvants, C: mAlum vaccine, $\mathrm{D}$ : Alum vaccine.

\section{Discussion}

Enhancement of the immune response against invading agents by vaccination has been used over the recent century [15]. Leptospirosis is one of the most common zoonotic diseases, and has widespread distribution in the world. By the development of vaccine delivery strategies in recent decades for well induction of immunity and improved patient compliance, the design and development or modification of adjuvants for the immune response alleviation and direction has increasingly become important [16]. In this respect, using the incredible potential of different adjuvants such as modified aluminium hydroxide and oil adjuvants is among the best pioneer options. So, selection of the best combination of vaccine plus adjuvants is necessary [17].

New discoveries have revealed that vitamin A is a key regulator of immune responses. This vitamin has a different role in the immune system [18]. Vitamin A enhances DC Maturation and antigenpresenting capacity by RXR Receptors. This effect has been started to promote T-helper-2 (TH2)-cell differentiation. Furthermore, vitamin $\mathrm{A}$ in the presence of transforming growth factor- $\beta$ (TGF $\beta$ )blocks the differentiation of $\mathrm{T}$ helper 17 (TH17) cells, at last give rise fork head box protein 3 (FOXP3)+regulatory $\mathrm{T}$ (TReg) cells and down regulating receptor-related orphan receptor- $\gamma \mathrm{t}(\mathrm{ROR} \gamma \mathrm{t})[19,20]$.

\begin{tabular}{|c|c|c|c|c|c|}
\hline NO & $\begin{array}{l}\text { Oligo } \\
\text { name }\end{array}$ & Sequence (5-3) & $\mathrm{Tm}$ & $\begin{array}{l}\text { CG } \\
\text { content }\end{array}$ & $\begin{array}{l}\text { Gene bank } \\
\text { accession } \\
\text { number }\end{array}$ \\
\hline 1 & $\begin{array}{l}\text { TNF- } \alpha \\
\text { forward }\end{array}$ & AACGGCATGTCTCTCAA & 50.4 & $47.10 \%$ & AF046215 \\
\hline 2 & $\begin{array}{l}\text { TNF- } \alpha \\
\text { reverse }\end{array}$ & AGTCGGTCACCTTTCT & 49.2 & $50 \%$ & \\
\hline 3 & $\begin{array}{l}\text { IFN-y } \\
\text { forward }\end{array}$ & GACAACCAGGCCATCC & 54.3 & $62.50 \%$ & AF034482 \\
\hline 4 & $\begin{array}{l}\text { IFN-y } \\
\text { reverse }\end{array}$ & CAAAACAGCACCGACT & 49.2 & $50 \%$ & \\
\hline 5 & $\begin{array}{l}\text { IL10- } \\
\text { forward }\end{array}$ & $\begin{array}{l}\text { TGGACAACATACTACTCA } \\
\text { CTG }\end{array}$ & 55.9 & $42.90 \%$ & AF046210 \\
\hline 6 & $\begin{array}{l}\text { IL10- } \\
\text { reverse }\end{array}$ & $\begin{array}{l}\text { GATGTCAAATTCATTCAT } \\
\text { GGC }\end{array}$ & 54 & $38.10 \%$ & \\
\hline 7 & $\begin{array}{l}\beta \text {-actin } \\
\text { forward }\end{array}$ & TCTACAACGAGCTGCG & 51.7 & $56.10 \%$ & AF046210 \\
\hline 8 & $\begin{array}{l}\beta \text {-actin } \\
\text { reverse }\end{array}$ & CAATTTCCCTCTCGGC & 51.7 & $56.30 \%$ & \\
\hline 9 & $\begin{array}{l}\text { IL4- } \\
\text { forward }\end{array}$ & $\begin{array}{l}\text { ATCCTGCTCTGCCTTCTA } \\
\text { GCATGT }\end{array}$ & 62.7 & $50 \%$ & AF046213 \\
\hline 10 & $\begin{array}{l}\text { IL4- } \\
\text { reverse }\end{array}$ & $\begin{array}{l}\text { TTCTTCAAGCACAGGGT } \\
\text { CACCTCA }\end{array}$ & 62.7 & $50 \%$ & \\
\hline 11 & $\begin{array}{l}\text { IL12p40- } \\
\text { forward }\end{array}$ & $\begin{array}{l}\text { CTTCCTGAAATGCGAGG } \\
\text { CAGCAAA }\end{array}$ & 62.7 & $50 \%$ & AF046211 \\
\hline 12 & $\begin{array}{l}\text { IL12p40- } \\
\text { reverse }\end{array}$ & $\begin{array}{l}\text { AGCTACTGCTGCTCTTG } \\
\text { ACGTTGA }\end{array}$ & 62.7 & $50 \%$ & \\
\hline 13 & $\begin{array}{l}\text { HPRT- } \\
\text { forward }\end{array}$ & $\begin{array}{l}\text { ACATTATGGCCCTCTTGT } \\
\text { GTGCTGA }\end{array}$ & 62.7 & $50 \%$ & AF047041 \\
\hline 14 & $\begin{array}{l}\text { HPRT- } \\
\text { reverse }\end{array}$ & $\begin{array}{l}\text { GGTTGTACTGTTTGACAA } \\
\text { AGGAAAGC }\end{array}$ & 62.7 & $50 \%$ & \\
\hline
\end{tabular}

Table 4: Primers used in this study, Tm and GC contact.

Other key topics to be discussed in it are Absorbing power [21,22]. Enclosed antigens in adjuvants are more slowly delivered from the injection site; however, kinetics is mostly dependent on the intensity of adsorption. It is commonly thought that adsorption of antigens to adjuvants is definitive to the effects of adjuvants [3,23]. The maintenance of antigens at the injection site authorizes time for inflammatory cells and antigen-presenting cells to collect at the injection site and interact with vaccines $[24,25]$. What we know is that regulation and stimulation of the immune system by Alum are independent TLR.

Different methods such as cell damage, physicochemical parameter, cathepsin B, NALP3, IL1 $\beta$, IL18, PGE2, and interaction of CD80/86 with $\mathrm{CD} 28$ have been proposed for activation of the immune system by adjuvants $[2,26]$. The majority of the researchers, who have studied the Leptospiral inflammation, have found that Leptospira can induce a remarkable increase in the human inflammatory cell and expression of IFN- $\gamma$, TNF- $\alpha$ and IL-12 receptor [27].

The success, find combination of mAlum-vaccine refers to its capability to promote both innate and adaptive immune responses. On the other hand, it has the ability to direct activation of DCs and rise of 
Citation: Banihashemia R, Baradaran B, Tebianian M, Tadayon K, Ebrahimi SM, et al. (2016) Improved Alum Containing Adjuvant by Vitamin A for Enhancing Immune Responses and Efficacy of Leptospira Vaccine in Hamster Model. J Vaccines Vaccin 7: 342. doi: $10.4172 / 2157-7560.1000342$

Page 6 of 7

MHC II and CD flowing the challenge of human monocytes with tetanus toxoid and Alum adjuvants [14,28]. By this method, the antigen joined to the surface of Alum (can be slowly delivered) and vitamin A (activation of DC and rise MHC class 2) we could access consistent potent antibody response good [29].

Lympho-proliferative response tests showed that mAlum Adjuvants caused the highest proliferative reaction compared to other adjuvants. Our results indicated that both mAlum and Alum induced noticeably higher level and long-term humoral responses (at week 64 posttreatment). Also, efficient maintenance a very strong Th1-type immune response was impelled following vaccination with an inactivated bacterial vaccine with aluminum hydroxide adjuvant, and the contention of $\gamma \delta$ T cells in the cellular response was observed [10,30]. In this study, we evaluated Th1 responses, by changing some physicochemical parameters and adding Vitamin A. Moreover, induction of Th1-type cellular immune response is correlated with the protection generated by the bovine Leptospira vaccine against $L$. borgpetersenii serovar hardjo. These data, establish that mAlum adjuvants can stimulate the production of type I cytokines involved in cellular immunity $[9,10,31]$. We know that expression of cytokines is done at different times. In the challenged of hamster model, after vaccination, TNF- $\alpha$, IFN- $\gamma$ and IL- 12 were expressed about 1 hour post-vaccination whereas IL-4 and IL-10 were prominent 1 to 2 days post-challenge [3,32].

The pathological lesions like necrosis and fibrosis seem to be due to the effects of inflammatory reactions [25,33]. Cytokines have been proposed to regulate tissue damage in acute lung injury and pulmonary fibrosis, and similar mechanism of tissue damage and errant repair may also occur in renal tissue infection with Leptospira. Furthermore, protection due to the immune response induced in the hamsters after getting mAlum showed prolonged survived rats, and reduced severity of pathological lesions compared to the Alum and without adjuvant. In conclusion, modified Alum adjuvants with whole Leptospira induced an effective and long-term immune response and maintenance protection, and could be considered as an appropriate vaccine prevention and therapy strategy provided that all physicochemical parameters and vitamin A that influence the immune responses take into consideration [11,34].

\section{Acknowledgements}

This work was completely financed with the state funds from the Razi vaccine and serum research institute under grant number 2-18-18-90065. All staffs of the aerobic bacterial research and vaccine production department of Razi institute as well as Dr. $\mathrm{H}$ Mohammadpur, a highly respected Ph.D candidate at the Tarbiat Modares Medical University are thanked for their contribution to the conduct of this research.

\section{Declaration of Interest}

The authors declare no conflicts of interest. The authors alone are responsible for the content of this manuscript.

\section{References}

1. Sykes JE, Hartmann K, Lunn KF, Moore GE, Stoddard RA, et al. (2011) 2010 ACVIM small animal consensus statement on leptospirosis: diagnosis, epidemiology, treatment, and prevention. J Vet Intern Med 25: $1-13$.
2. Kool M, Fierens K, Lambrecht BN (2012) Alum adjuvant: some of the tricks of the oldest adjuvant. J Med Microbiol 61: 927-934.

3. Zuerner RL (2015) Host response to leptospira infection. Curr Top Microbiol Immunol 387: 223-250.

4. Banihashemi R (2013) Development of Leptospira Killed Whole Culture Vaccine Using Different Adjuvants and Evaluation of Humoral Immune Response in Hamsters. J Vaccines Vaccin 4: 185.

5. Moazenijula G, Jabbari AR, Geravand MM, Banihashemi R, Hajizadeh A (2011) Improvement of trivalent leptospira vaccine by removal of anaphylactic agents. Trop Anim Health Prod 43: 1471-1474.

6. Yan W, Faisal SM, McDonough SP, Chang CF, Pan MJ, et al. (2010) Identification and characterization of OmpA-like proteins as novel vaccine candidates for Leptospirosis. Vaccine 28: 2277-2283.

7. Cao Y, Faisal SM, Yan W, Chang YC, McDonough SP, et al. (2011) Evaluation of novel fusion proteins derived from extracellular matrix binding domains of LigB as vaccine candidates against leptospirosis in a hamster model. Vaccine 29: 7379-7386.

8. Kim HJ, Prithiviraj K, Groathouse N, Brennan PJ, Spencer JS (2013) Gene Expression Profile and Immunological Evaluation of Unique Hypothetical Unknown Proteins of Mycobacterium leprae by Using Quantitative Real-Time PCR. Clin Vaccine Immunol 20: 181-190.

9. Brewer JM, Conacher M, Hunter CA, Mohrs M, Brombacher F, et al. (1999) Aluminium hydroxide adjuvant initiates strong antigen-specific Th2 responses in the absence of IL-4-or IL-13-mediated signaling. J Immunol 163: 6448-6454.

10. Brewer JM, Conacher M, Satoskar A, Bluethmann H, Alexander J (1996) In interleukin-4-deficient mice, alum not only generates $\mathrm{T}$ helper 1 responses equivalent to Freund's complete adjuvant, but continues to induce T helper 2 cytokine production. Eur J Immunol 26: 2062-2066.

11. Pijanowski L, Scheer M, Verburg-van Kemenade BM, Chadzinska M (2015) Production of inflammatory mediators and extracellular traps by carp macrophages and neutrophils in response to lipopolysaccharide and/or interferon- $\hat{\mathrm{I}}^{3} 2$. Fish Shellfish Immunol 42: 473-482.

12. Faisal SM, Yan W, McDonough SP, Chang YF, et al. (2009) Leptospira immunoglobulin-like protein A variable region (LigAvar) incorporated in liposomes and PLGA microspheres produces a robust immune response correlating to protective immunity. Vaccine 27: 378-387.

13. Faisal SM, Yan W, McDonough SP, Mohammed HO, Divers TJ, et al. (2009) Immune response and prophylactic efficacy of smegmosomes in a hamster model of leptospirosis. Vaccine 27: 6129-6136.

14. Chang YF, Chen CS, Palaniappan RU, He H, McDonough SP, et al. (2007) Immunogenicity of the recombinant leptospiral putative outer membrane proteins as vaccine candidates. Vaccine 25: 8190-8197.

15. Faisal SM, Chen JW, McDonough SP, Chang CF, Teng CH, et al. (2011) Immunostimulatory and antigen delivery properties of liposomes made up of total polar lipids from non-pathogenic bacteria leads to efficient induction of both innate and adaptive immune responses. Vaccine 29: 2381-2391.

16. Sauvageau C, Dubé E, Bradet R, Mondor M, Lavoie F, et al. (2013) Immunization services offered in Québec (Canada) pharmacies. Hum Vaccin Immunother 9: 1943-1949.

17. Fraga TR, Barbosa AS, Isaac L (2011) Leptospirosis: aspects of innate immunity, immunopathogenesis and immune evasion from the complement system. Scand J Immunol 73: 408-419.

18. Rimaniol AC, Gras G, Verdier F, Capel F, Grigoriev VB, et al. (2004) Aluminum hydroxide adjuvant induces macrophage differentiation towards a specialized antigen-presenting cell type. Vaccine 22: 3127-3135.

19. Reed SG, Orr MT, Fox CB (2013) Key roles of adjuvants in modern vaccines. Nat Med 19: 1597-1608.

20. Woodland DL (2016) Vitamin A Influence on B Cell Class Switch Recombination. Viral Immunol 29: 73.

21. Wagner S, Hufnag K, Pacios LFF, Roth-Walter F, Bianchini R, et al. (2016) Binding of the Active Vitamin A Metabolite Retinoic Acid to the Major Cows Milk Allergen Bos d 5 Down-Regulates T-Cell Responses. Aaaai 127: Page AB407. 
Citation: Banihashemia R, Baradaran B, Tebianian M, Tadayon K, Ebrahimi SM, et al. (2016) Improved Alum Containing Adjuvant by Vitamin A for Enhancing Immune Responses and Efficacy of Leptospira Vaccine in Hamster Model. J Vaccines Vaccin 7: 342. doi: $10.4172 / 2157-7560.1000342$

Page 7 of 7

22. Paterson WD, Stewart JE, Zwicker BM, et al. (1976) Phagocytosis as a cellular immune response mechanism in the American lobster, Homarus americanus. J Invertebr Pathol 27: 95-104.

23. Musher DM, Luchi MJ, Watson DA, Hamilton R, Baughn RE (1990) Pneumococcal polysaccharide vaccine in young adults and older bronchitics: determination of IgG responses by ELISA and the effect of adsorption of serum with non-type-specific cell wall polysaccharide. J Infect Dis 161: 728-735.

24. Vecchi S, Bufali S, Skibinski DA, O'Hagan DT, Singh M (2012) Aluminum adjuvant dose guidelines in vaccine formulation for preclinical evaluations. J Pharm Sci 101: 17-20.

25. Morefield GL, Sokolovska A, Jiang D, HogenEsch H, Robinson JP, et al. (2005) Role of aluminum-containing adjuvants in antigen internalization by dendritic cells in vitro. Vaccine 23: 1588-1595.

26. Shahabi S, Azizi H, Mazloomi E, Tappeh KH, Seyedi S, et al. (2014) A novel adjuvant, the mixture of alum and naltrexone, augments vaccineinduced immunity against Plasmodium berghei. Immunological investigations 43: 653-666.

27. McCarthy DP, Hunter ZN, Chackerian B, Shea LD, Miller SD (2014) Targeted immunomodulation using antigen-conjugated nanoparticles. Wiley Interdiscip Rev Nanomed Nanobiotechnol 6: 298-315.

28. Bergmann-Leitner ES, Leitner WW (2014) Adjuvants in the Driver's Seat: How Magnitude, Type, Fine Specificity and Longevity of Immune
Responses Are Driven by Distinct Classes of Immune Potentiators. Vaccines 2: 252-296.

29. Marchioro SB (2013) Immune responses induced by replication-defective adenovirus expressing the C-terminal portion of the Mycoplasma hyopneumoniae P97 adhesin. Clin Vaccine Immunol 14: 767-774.

30. Hogenesch H (2013) Mechanism of immunopotentiation and safety of aluminum adjuvants. Front Immunol 3: 406.

31. Ulanova M, Tarkowski A, Hahn-Zoric M, Hanson LA (2001) The common vaccine adjuvant aluminum hydroxide up-regulates accessory properties of human monocytes via an interleukin-4-dependent mechanism. Infect Immun 69: 1151-1159.

32. Guo Y, Fukuda T, Nakamura S, Bai L, Xu J, et al. (2015) Interaction between Leptospiral Lipopolysaccharide and Toll-like Receptor 2 in Pig Fibroblast Cell Line, and Inhibitory Effect of Antibody against Leptospiral Lipopolysaccharide on Interaction. Asian Australas J Anim Sci 28: 273-279.

33. Mogensen TH (2009) Pathogen recognition and inflammatory signaling in innate immune defenses. Clin Microbiol Rev 22: 240-273.

34. Vijayachari P, Vedhagiri K, Mallilankaraman K, Mathur PP, Sardesai NY, et al. (2015) Immunogenicity of a novel enhanced consensus DNA vaccine encoding the leptospiral protein LipL45. Hum Vaccin Immunother 11: 1945-1953. 